\title{
Aqueous Voltammetry in the Near Absence of Electrolyte
}

Xiuting Li, ${ }^{\mathrm{a}, \dagger}$ Christopher Batchelor-McAuley, ${ }^{\mathrm{a}, \dagger}$ Eduardo Laborda ${ }^{\mathrm{b}}$ and Richard G.

Compton $^{\mathrm{a}, *}$

a Department of Chemistry, Physical \& Theoretical Chemistry Laboratory, Oxford

University, Oxford, OX1 3QZ, United Kingdom.

b Departamento de Química Física, Facultad de Química, Universidad de Murcia, 30100, Murcia, Spain

${ }^{\dagger}$ These authors contributed equally to this work.

\section{Corresponding Author}

*Correspondence to: richard.compton@chem.ox.ac.uk

Telephone number: +44(0) 1865275957 


\begin{abstract}
In order to minimize the incidence of the $\mathrm{CO}_{2}$ hydrolysis and conduct aqueous electrochemistry in the virtual absence of electrolyte, a novel methodology is developed to achieve the near minimum conductivity $\left(\sim 60 \mathrm{nS} \mathrm{cm}{ }^{-1}\right)$ for an aqueous solution through in-situ deionization with ion exchange resin beads. Aqueous electrochemistry studying the oxidations of platinum, ferrocenemethanol and hydrogen $\left(\mathrm{H}_{2}\right)$ were conducted in the near complete absence of trace ionic species at a platinum microelectrode $(\mathrm{d}=10 \mu \mathrm{m})$. Both surface and solution phase electrochemical reactions were clearly observed, indicating that under these conditions there is a sufficiently compressed double layer for an interfacial electron transfer to be driven and the iR effects are significantly smaller than theoretically expected.
\end{abstract}

\title{
Introduction
}

The use of excess supporting electrolyte when studying interfacial redox reactions is near ubiquitous. Purportedly the electrolyte serves two major functions: First, it contracts the electrochemical double layer to length scales comparable to the electron tunnelling distance. Second, it ensures - even with the occurrence of an interfacial electrochemical reaction - that a significant potential gradient does not build-up in the depletion zone surrounding the electrode ${ }^{[1]}$ Hence, when the question of 'how much supporting electrolyte is required for a voltammetric experiment' is raised, the focus is commonly on the solution phase ionic strength required, such that, the mass-transport of material to and from the electrode can be considered a diffusion only process, and the potential drop between the reference electrode and the position at which electron transfer occurs is negligible. At a macroelectrode support ratios in excess of 100 are often required to avoid any detectable broadening of the voltammetric peak due to ohmic distortion. ${ }^{[2]}$ Notably, through the use of micron scale 
electrodes the requirements of this latter point can be relaxed, enabling experiments to be performed in more resistive media. ${ }^{[3]}$ The vast majority of studies on this subject have been carried out in organic solvents (notably acetonitrile, see SI section 1$)^{[3 a, 3 b, 4]}$ and only very few studies focus on aqueous electrochemistry with uncharged species where there is no 'self-support'. ${ }^{\text {[5] }}$ This work serves to explore how much electrolyte is needed in an aqueous environment for electrochemical analysis to be performed using a micro-electrode. A new methodology is developed to provide in-situ deionization via the use of the ion-exchange resin beads; this enables the production and maintenance of bulk conductivity of the solution down to $60 \mathrm{nS} \mathrm{cm}^{-1}$. Subsequently, the voltammetry of surface and solution phase electrochemical reactions in ultra-low conductivity water are examined. Comparison of the voltammetric responses in the solution with and without the treatment of the ion-exchange resin beads demonstrates how the conductivity provided by dissolved $\mathrm{CO}_{2}$ is sufficient to enable electrochemical analysis to be performed.

\section{Results and discussion}

In order to study a redox reaction in low ionic strength media the conductivity of laboratory grade 'ultrapure water' needs to be considered. All commercial 'type $1^{\text {,[6] }}$ water systems provide an in-line measure of the produced water conductivity/resistivity. The value of 0.055 $\mu \mathrm{S} \mathrm{cm} \mathrm{cm}^{-1}$ (or equivalently $18.2 \mathrm{M} \Omega \mathrm{cm}$ at $25^{\circ} \mathrm{C}$ ) is commonly used as a measure to evidence the absence of ionic impurities. However, in our experiments we found that within tens of seconds of leaving the purification device the solution jumps from a conductivity of $0.055 \mu \mathrm{S}$ $\mathrm{cm}^{-1}$ to $\sim 0.4 \mu \mathrm{S} \mathrm{cm}^{-1}$. As shown in Table 1 an air equilibrated water sample is found to have conductivity of circa $1.3 \mu \mathrm{S} \mathrm{cm}^{-1}$ and after vigorous degassing with high purity argon a conductivity of $\sim 0.2 \mu \mathrm{S} \mathrm{cm} \mathrm{cm}^{-1}$ is attainable. These results are fully consistent with the influence of dissolved carbon dioxide on the solution conductivity, where the pseudo-first 
order hydration kinetics of dissolved $\mathrm{CO}_{2}$ is $0.0375 \pm 0.002 \mathrm{~s}^{-1}\left(\mathrm{t}_{1 / 2} \sim 18.5 \mathrm{~s}\right) .{ }^{[7]}$ Consequently, after leaving the purification device in a near ion-free condition, due to the fast hydration of the carbon dioxide forming $\mathrm{H}_{2} \mathrm{CO}_{3}$ and hence $\mathrm{HCO}_{3}^{-}$, the system relaxes towards equilibrium resulting in the significant increase in the conductivity. From the measured solution phase conductivity and under an assumption of the ions present in solution, the ionic composition $\left(\mathrm{H}^{+}, \mathrm{OH}^{-}\right.$and $\left.\mathrm{HCO}_{3}{ }^{-}\right)$of the water can be readily inferred as presented in Table 1 (see SI section 4 for details of the calculation).

Table 1. Conductivity of different $\mathrm{H}_{2} \mathrm{O}$ samples referenced to $25^{\circ} \mathrm{C}$ and their inferred composition.

\begin{tabular}{|c|c|c|c|c|c|}
\hline $\mathrm{H}_{2} \mathrm{O}$ samples & $\begin{array}{l}\text { Conductivity } \\
\text { Measured } \\
\quad\left(\mu \mathrm{S} \mathrm{cm}^{-1}\right)\end{array}$ & $\begin{array}{c}{\left[\mathrm{H}^{+}\right]} \\
\left(\mathrm{nmol} \mathrm{L}{ }^{-1}\right)\end{array}$ & $\begin{array}{c}{\left[\mathrm{OH}^{-}\right]} \\
\left(\mathrm{nmol} \mathrm{L}{ }^{-1}\right)\end{array}$ & 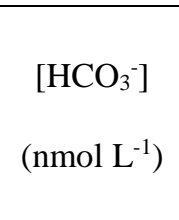 & $\begin{array}{c}{\left[\mathrm{CO}_{2}\right]} \\
\left(\mathrm{nmol} \mathrm{L}{ }^{-1}\right)\end{array}$ \\
\hline Air saturated & $1.33 \pm 0.02$ & $3,370 \pm 50$ & $3.00 \pm 0.05$ & $3,370 \pm 50$ & $25,500 \pm 800$ \\
\hline $\begin{array}{c}\text { Ar degassed }^{\mathrm{a}} \\
\text { (lowest achieved) }^{\mathrm{b}}\end{array}$ & $\begin{array}{c}0.36 \pm 0.01 \\
(0.22 \pm 0.01)\end{array}$ & $\begin{array}{l}909 \pm 25 \\
(551 \pm 26)\end{array}$ & $\begin{array}{c}11.1 \pm 0.3 \\
(18.3 \pm 0.9)\end{array}$ & $\begin{array}{l}897 \pm 26 \\
(532 \pm 26)\end{array}$ & $\begin{array}{l}1,830 \pm 100 \\
(660 \pm 65)\end{array}$ \\
\hline In-line measurement & $0.055 \pm 0.001$ & $100 \pm 4$ & $100 \pm 4$ & NA & Unknown \\
\hline IEx Beads treated & $0.059 \pm 0.002$ & $116 \pm 7$ & $87.3 \pm 5.9$ & $28.5 \pm 13.3$ & $7.41 \pm 3.76$ \\
\hline
\end{tabular}

${ }^{a}$ Values obtained in the electrochemistry cell $(100 \mathrm{~mL})$ with a gas flow of $\sim 100 \mathrm{~mL} \mathrm{~min}^{-1}$.

${ }^{\mathrm{b}}$ Values obtained by using a big volume of cell $(1 \mathrm{~L})$ which was vigorously degassed with Ar.

Mixed bed ion-exchange resins with sulfonic acid and quaternary ammonium functional groups work by trapping their counter ions in the target solution along with the accompanying release of other ions notably $\mathrm{H}^{+}$or $\mathrm{OH}^{-}$. In this work the use of $10 \mathrm{~g}$ Dowex ion exchange (IEx) resin beads (MR-450 UPW) in a well-sealed cell containing $60 \mathrm{~mL}$ of 'ultrapure' water led to a decrease in the conductivity in the electrochemical cell down to 
$0.059 \mu \mathrm{S} \mathrm{cm} \mathrm{cm}^{-1}$. Note a conductivity of $0.055 \mu \mathrm{S} \mathrm{cm}^{-1}$ was achieved initially but the conductivity increased slightly $\left(<0.060 \mu \mathrm{S} \mathrm{cm} \mathrm{cm}^{-1}\right)$ upon cessation of stirring and argon bubbling. By trapping the formed carbonate anion, these beads also enable the near complete removal of $\mathrm{CO}_{2}$ from the aqueous phase, with an estimated total carbon dioxide content (both hydrated and non-hydrated) in the ion-exchange resin bead treated water of 36 nM (see Table 1).

Having enabled the production and maintenance of ultra-low conductivity water, first we investigate the cyclic voltammetry $(\mathrm{CV})$ of a Pt microelectrode $(\mathrm{d}=10 \mu \mathrm{m})$ under these bulk ultra-low conductivity conditions (see experimental section for full details). Prior to measurement the conductivity probe was taken out of the solution and an Ar atmosphere maintained. Figure 1 (A) shows the initial voltammetric curves which start at $0.0 \mathrm{~V}$ vs Ag wire and proceed anodically to different first vertex potentials $\left(1.2 \mathrm{~V}\left(1^{\text {st }} \mathrm{scan}\right), 1.0 \mathrm{~V}\right.$ (2 $^{\text {nd }}$ scan), $0.8 \mathrm{~V}$ ( $3^{\text {rd }}$ scan $), 0.6 \mathrm{~V}\left(4^{\text {th }}\right.$ scan $)$ and $0.4 \mathrm{~V}\left(5^{\text {th }}\right.$ scan $)$ vs Ag wire). In all cases to avoid ionic contamination a clean silver wire electrode has been used as a pseudo reference electrode and the counter electrode was situated at a distance of over a centimetre away from the working electrode. The result presented in Figure 1 (A) is that even in this ultra-low conductivity water a clear voltammetric response is recorded. A broad oxidation wave is observed at $\sim+0.5 \mathrm{~V}$ and a corresponding reductive feature at $\sim-0.5 \mathrm{~V}$, this irreversible feature is ascribed as relating to the oxidation and reduction of the platinum surface. ${ }^{[8]}$ A further small oxidation peak at around $-0.4 \mathrm{~V}$ vs Ag wire is observed and assigned to the oxidation of the under-potential deposited hydrogen $\left(\mathrm{H}_{\text {upd }}\right) .{ }^{[9]}$ As shown in the inset of Figure 1 (A), the peak is not seen when the second vertex potential is set at a low overpotential (-0.7 V vs Ag wire) where no significant $\mathrm{H}_{\text {upd }}$ forms. 

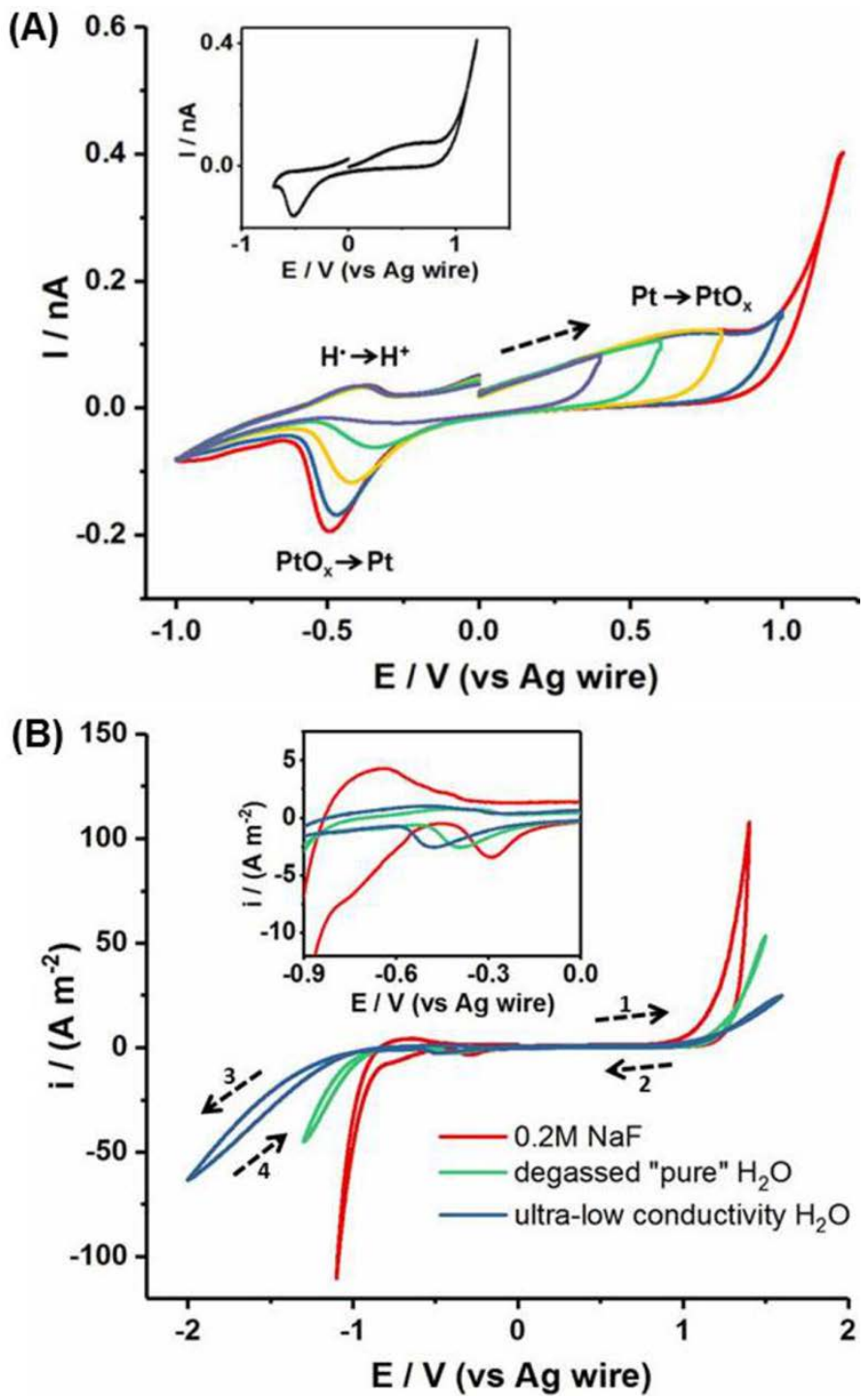

Figure 1. (A) Voltammogram for a Pt microelectrode $(\mathrm{d}=10 \mu \mathrm{m})$ in ultra-low conductivity $\mathrm{H}_{2} \mathrm{O}$ $(0.059 \mu \mathrm{S} / \mathrm{cm})$. Inset: voltammogram with second vertex potential at $-0.7 \mathrm{~V}$. Scan rate: $50 \mathrm{mV} / \mathrm{s}$. (B) Voltammogram for Pt microelectrode $(\mathrm{d}=10 \mu \mathrm{m})$ in ultra-low conductivity $\mathrm{H}_{2} \mathrm{O}$ (blue, $0.059 \mu \mathrm{S} / \mathrm{cm}$ ), degassed "pure” water (green, $0.36 \mu \mathrm{S} / \mathrm{cm}$ ) and $0.20 \mathrm{M} \mathrm{NaF}$ (red, $16 \mathrm{mS} / \mathrm{cm}$ ). Inset: zoom-in image. Dashed arrows show the scanning directions.

The voltammetric profile shown in Figure 1 closely mirrors that obtained for the polycrystalline platinum electrode in a solution containing $0.20 \mathrm{M} \mathrm{NaF}$ (Figure S5). The use of a pseudo reference electrode in the present work precludes direct comparison of potentials with other literature reported measurements; however, the shape of the voltammetry at the Pt electrode closely resembles that found in the literature for polycrystalline surfaces. ${ }^{[9]}$ 
Furthermore, we comment that the response of a Pt macroelectrode $(\mathrm{d}=1.65 \mathrm{~mm})$ under comparable ultra-low conductivity $\mathrm{H}_{2} \mathrm{O}$ conditions does not exhibit a voltammetric response (SI Section 6) and only shows resistive behaviour. This likely arises due to the larger capacitances associated with the macroelectrode leading to a higher cell time constant under the high resistive conditions.

In addition to the surface redox reaction processes the oxidative and reductive breakdown of solvent is also measurable in ultra-low conductivity water. Figure 1 (B) depicts the voltammetric response of three solutions of differing ionic strength, highlighting how the electrochemical window is correspondingly altered. It is observed that the potential window in the ultra-low conductivity $\mathrm{H}_{2} \mathrm{O}$ (blue line) is larger than that in the degassed "pure" water (green line) and 0.20 M NaF solution (red line). The fully supported media (NaF solution) shows the narrowest potential window. Although solvent break down is a complex process it is apparent that even in the absence of any significant electrolyte concentrations a Faradaic process can be driven at the electrode surface. Similarly extended potential windows in the ultra-low conductivity $\mathrm{H}_{2} \mathrm{O}$ are also observed for $\mathrm{Au}$ microelectrode and $\mathrm{C}$ microelectrodes under comparable conditions (Figure S7).

Having evidenced the ability to record a voltammetric response in ultra-low conductivity water at a micro-electrode, we next consider the voltammetric response of a solution-phase redox active moiety. Figure 2 shows the cyclic voltammetric responses of $\mathrm{FCCH}_{2} \mathrm{OH}$ oxidation at the Pt microelectrode $(\mathrm{d}=10 \mu \mathrm{m})$ in the ultra-low conductivity $\mathrm{H}_{2} \mathrm{O}$ (yellow), degassed "pure” $\mathrm{H}_{2} \mathrm{O}$ (blue) and $0.20 \mathrm{M} \mathrm{NaF}$ solution (red) respectively. In all three cases a clear oxidative voltammetric wave is observed with steady-state currents of $0.76 \mathrm{nA}$ for the ultra-low conductivity $\mathrm{H}_{2} \mathrm{O}, 1.49 \mathrm{nA}$ for the degassed "pure" $\mathrm{H}_{2} \mathrm{O}$ and $1.54 \mathrm{nA}$ for $0.20 \mathrm{M}$ 
$\mathrm{NaF}$ solution. The small reduction features shown at around $-0.2 \mathrm{~V}$ in the backward scans is ascribed to Pt oxide reduction (see Figure 2 inset).

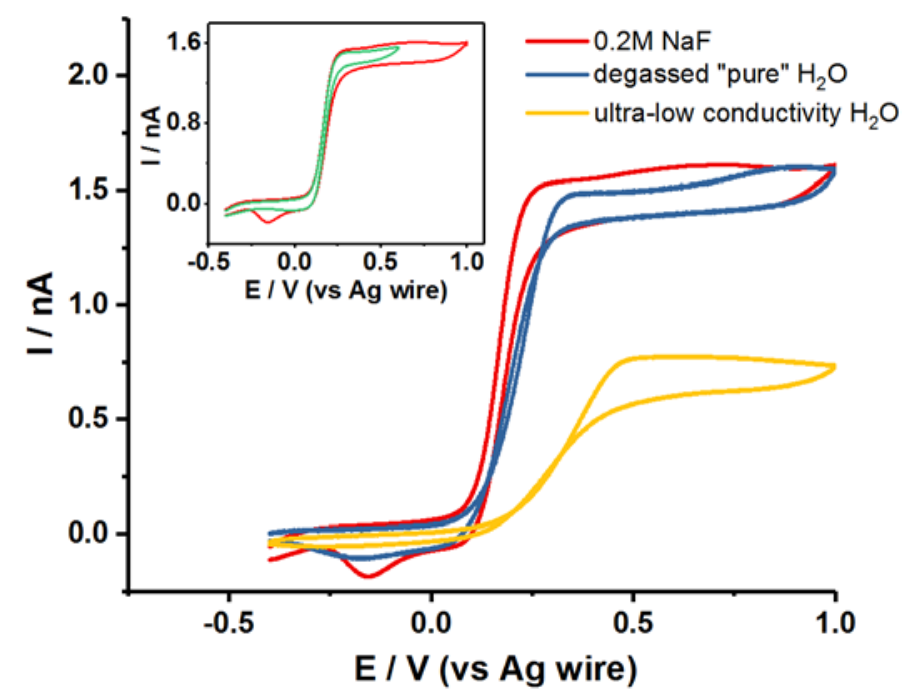

Figure 2. Voltammogram of $1 \mathrm{mM} \mathrm{FcCH} \mathrm{F}_{2} \mathrm{OH}$ oxidation at a Pt microelectrode $(\mathrm{d}=10 \mu \mathrm{m})$ in $0.20 \mathrm{M}$ $\mathrm{NaF}$ (red, $16 \mathrm{mS} / \mathrm{cm}$ ), degassed "pure” $\mathrm{H}_{2} \mathrm{O}$ (blue, $0.36 \mu \mathrm{S} / \mathrm{cm}$ ) and ultra-low conductivity $\mathrm{H}_{2} \mathrm{O}$ (yellow, $0.059 \mu \mathrm{S} / \mathrm{cm}$ ). Inset: voltammogram with the vertex potential at $0.6 \mathrm{~V}$ and $1.0 \mathrm{~V}$. Scan rate: $50 \mathrm{mV} / \mathrm{s}$.

The steady state values for the oxidation in the two higher ionic strength cases are in agreement with the calculated diffusion only predicted steady state current of $1.5 \mathrm{nA}$ for $\mathrm{FcCH}_{2} \mathrm{OH}$ oxidation (diffusion coefficient $=7.8 \times 10^{-10} \mathrm{~m}^{2} / \mathrm{s}$ ) ${ }^{[10]}$ at a microelectrode with the radius of $5.0 \mu \mathrm{m} .{ }^{[11]}$ Moreover, the oxidative wave in degassed "pure” $\mathrm{H}_{2} \mathrm{O}(0.36 \mu \mathrm{S} / \mathrm{cm})$ is almost equivalent to that in the fully supported media $(0.20 \mathrm{M} \mathrm{NaF}$ solution, $16 \mathrm{mS} / \mathrm{cm})$, indicating that the ionic strength of this solution $(0.36 \mu \mathrm{S} / \mathrm{cm})$ is sufficient to predominantly suppress any Ohmic drop effects associated with the oxidation process, ${ }^{[12]}$ which notably contrasts with theoretical predictions (see SI section 8 ). ${ }^{[13]}$ While it is found that the steady state current of $0.76 \mathrm{nA}$ in the ultra-low conductivity $\mathrm{H}_{2} \mathrm{O}$ is lower than the expected value (1.5 nA), this is believed to result from the adsorption of the $\mathrm{FcCH}_{2} \mathrm{OH}$ onto the IEx resin 
beads $^{[14]}$, hence decreasing the effective concentration of $\mathrm{FcCH}_{2} \mathrm{OH}$ in solution (see SI section 9 for further evidence).

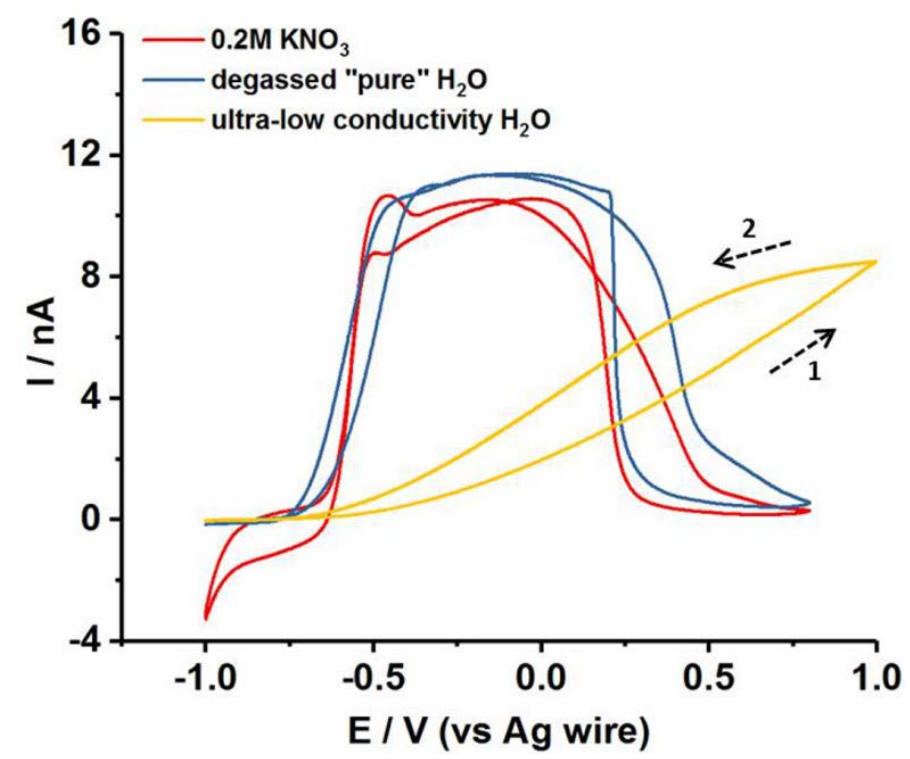

Figure 3. Voltammogram of $\mathrm{H}_{2}$ oxidation $(0.77 \mathrm{mM})^{[15]}$ at a Pt microelectrode $(\mathrm{d}=10 \mu \mathrm{m})$ in $0.20 \mathrm{M}$ $\mathrm{KNO}_{3}$ (red curve), degassed "pure” $\mathrm{H}_{2} \mathrm{O}$ (blue curve) and ultra-low conductivity $\mathrm{H}_{2} \mathrm{O}$ (yellow curve). Scan rate: $50 \mathrm{mV} / \mathrm{s}$.

As a paradigm of an 'inner-sphere' electrochemical reaction, the voltammetric response of hydrogen, $\mathrm{H}_{2}$, oxidation was further investigated in ultra-low conductivity water at a $\mathrm{Pt}$ microelectrode. Figure 3 shows the cyclic voltammogram of hydrogen oxidation at the Pt microelectrode $(\mathrm{d}=10 \mu \mathrm{m})$ in the ultra-low conductivity $\mathrm{H}_{2} \mathrm{O}$ (yellow), degassed "pure” $\mathrm{H}_{2} \mathrm{O}$ (blue) and $0.20 \mathrm{M} \mathrm{KNO}_{3}$ solution (red) respectively. In both the degassed "pure” $\mathrm{H}_{2} \mathrm{O}$ and $0.20 \mathrm{M} \mathrm{KNO}_{3}$ solution, the steady-state current is observed with a value of ca. $11 \mathrm{nA}$. It is smaller than that anticipated for a diffusion limited process (14.8 nA) due to the ratedetermining $\mathrm{H}_{2}$ adsorption to the $\mathrm{Pt}$ surface. ${ }^{[16]}$ Similar to $\mathrm{FCCH}_{2} \mathrm{OH}$ oxidation, the voltammetric response of hydrogen oxidation also shows almost identical oxidative waves in degassed "pure" $\mathrm{H}_{2} \mathrm{O}$ and in the fully supported media (0.20 $\mathrm{M} \mathrm{KNO}_{3}$ solution), further experimentally indicating that the Ohmic drop effects have been effectively suppressed and 
are negligible in the degassed "pure” $\mathrm{H}_{2} \mathrm{O}$, while a distorted but obvious wave from hydrogen oxidation is observed in the ultra-low conductivity $\mathrm{H}_{2} \mathrm{O}$.

The striking results in both cases of $\mathrm{FcCH}_{2} \mathrm{OH}$ oxidation and hydrogen oxidation indicate that for both an outer-sphere and inner-sphere electron transfer process even in essentially minimum conductivity possible for an aqueous solution there is a sufficiently compressed double layer for an interfacial electron transfer to be driven. Moreover, if ion-exchange beads are not used in the cell the electrochemical support provided by dissolved carbon dioxide is sufficient to ensure an essentially undistorted voltammetric response for the oxidation of a neutral species (where self-support is not feasible). Note that the above observations related to molecular species whereas chronoamperometric study of individual redox nanoparticles shows highly reduced signals in low supporting aqueous medium; ${ }^{[17]}$ this may reflect the significant difference between the nanoparticles and molecules in terms of size, surface charge and shape. Significantly differences regarding the ohmic drop effects is also seen between the ultra-low conductivity water and organic solvents, the experiments in the latter being compatible with current theoretical treatments of the ohmic drop (see SI section 8), whereas iR effects in water are significantly smaller than expected.

Following the pioneering work of Frumkin ${ }^{[18]}$ significant theoretical effort has been focused upon considering how the double layer may influence the kinetics of interfacial electron transfer reactions. As outlined in Section 2 and 3 of the SI the conventional view is that inorder for an electrochemical process to be "fully driven" the redox species must be situated outside of the double-layer structure. For the above experimental cases it is beneficial to consider the position at which electron transfers to or from the redox active species. For an 'outer-sphere' redox process the electroactive species needs to approach to within a tunnelling distance of the surface $(<1 \mathrm{~nm}$, the rate of electron tunnelling is exponentially 
dependent upon distance, $\exp (-\beta \mathrm{x})$, where $\beta$ is of the order of $1.6 \AA^{-1}$ in aqueous solution and $\mathrm{x}$ is the electron transfer distance. ${ }^{[19]}$ ); however, for an inner-sphere or surface bound reaction the redox moiety is necessarily situated within a chemical bond length of the metallic surface. For the above experiments, performed under ultra-low conditions of supporting electrolyte, the results plausibly indicate that self-ionisation of the solvent may be an important factor in determining the aqueous double layer structure under these low support conditions. However, more generally the ability for surface redox processes to be driven at a metallic interface, even in the presence of supporting electrolyte, may in itself provide direct evidence for the importance of the penetration of the electric field into the outer-most atomic metallic layer ${ }^{[20]}$ and the role of the structure and dielectric properties of the compact double layer in mitigating the influence of the electric field at micro- and nano-electrodes. ${ }^{[21]}$ We note that as ever greater progress is made in studying redox reactions at the nanoscale the structure of the double-layer becomes a more significant consideration. ${ }^{[21 \mathrm{a}, 21 \mathrm{~b}]}$ The present methodology to "clean" aqueous solution enables electrochemistry to be performed in the near absence of supporting electrolyte and provides a platform for fundamental studies on the electrical double layer structure, conductivity mechanisms (eg., solvent self-ionisation ${ }^{[4 \mathrm{e}]}$ and species self-ionisation), water behaviour at interfaces ${ }^{[22]}$ and under high electric fields, etc. This novel approach, with the incidence of the $\mathrm{CO}_{2}$ hydrolysis being avoided/minimized, also has the potential to build the so-called 'single-ion case' as defined previously ${ }^{[23]}$ in water.

\section{Conclusions}

A simple and efficient methodology was developed to prepare ultra-low conductivity $\mathrm{H}_{2} \mathrm{O}$ by in-situ deionizing $\mathrm{H}_{2} \mathrm{O}$ using the ion-exchange resin beads. With the present method, the $\mathrm{CO}_{2}$ hydrolysis is minimized and the bulk conductivity of solution is able to attain $60 \mathrm{nS} \mathrm{cm}^{-1}$. Compared with the degassed "pure” $\mathrm{H}_{2} \mathrm{O}$ and fully supported media (0.20 M NaF), the ultralow conductivity $\mathrm{H}_{2} \mathrm{O}$ shows an extended potential window. Characteristic platinum 
oxidation signals, steady state voltammetry of $\mathrm{FcCH}_{2} \mathrm{OH}$ oxidation and hydrogen oxidation responses are obtained in the ultra-low conductivity $\mathrm{H}_{2} \mathrm{O}$, demonstrating the feasibility of electrochemical reactions in aqueous media in the absence of the supporting electrolyte.

\section{Experimental section}

\section{Chemicals}

Sodium fluoride ( $\geq 99 \%, \mathrm{NaF})$ was purchased from Fluka (Buchs, Switzerland). Ferrocenemethanol (97\%, $\left.\mathrm{FcCH}_{2} \mathrm{OH}\right)$ was acquired from Santa Cruz Biotechnology (Santa Cruz, CA). Dowex monosphere MR-450 UPW was obtained from Sigma-Aldrich. Dowex monosphere MR-450 UPW is a bifunctional styrene-divinylbenzene (S-DVB)-based nonseparable, mixed-bed, gel-type, ion-exchange resin with sulfonic acid (350C UPW) and quaternary ammonium (550A UPW) functionality. Argon ( $\geq 99.998 \%$ Ar) and Hydrogen $\left(\geq 99.98 \% \mathrm{H}_{2}\right)$ was supplied from BOC, Surrey, U.K. All solutions were made up with deionised water (Millipore) at $298 \mathrm{~K}$, some of which, as stated specifically in the text, went through further treatment with the above ion-exchange resin beads (procedure shown below).

\section{Preparation and characterization of ultra-low conductivity $\mathrm{H}_{2} \mathrm{O}$}

$10 \mathrm{~g}$ ion-exchange resin beads were rinsed with $100 \mathrm{~mL}$ Millipore water for five times, and then mixed with $60 \mathrm{~mL}$ Millipore water in a glassy cell. The cell was sealed in which water was stirred and degassed with Ar for about 10 mins until its conductivity decreased to less than $60 \mathrm{nS} / \mathrm{cm}$. The conductivity probe (Mettler Toledo, InLab 742) with a proper range of 0.001-500 $\mu \mathrm{S} / \mathrm{cm}$ was kept in the water and measured in-situ by connecting to a portable conductivity meter (Mettler Toledo, Seven2Go $\mathrm{Gm}^{\mathrm{TM}} \mathrm{S} 3$ ). For $\mathrm{FcCH}_{2} \mathrm{OH}$ experiments, $10 \mathrm{~g}$ of the pre-cleaned ion-exchange resin beads was added into $60 \mathrm{~mL} \mathrm{FcCH}_{2} \mathrm{OH}$ solution (prepared by Millipore deionised water) and the mixture was stirred and degassed as above until the conductivity of the solution dropped to be around $60 \mathrm{nS} / \mathrm{cm}$. Hydrogen oxidation in ultra-low 
conductivity $\mathrm{H}_{2} \mathrm{O}$ was performed after bubbling $\mathrm{H}_{2} \mathrm{O}$ with $\mathrm{H}_{2}$ for 10 mins and the same cleaning strategy via the use of the ion-exchange resin beads was applied.

\section{Electrochemical measurements}

A platinum $(\mathrm{Pt})$ microelectrode $(\mathrm{d}=10 \mu \mathrm{m})$ was polished with diamond spray ( 1 and 0.1 microns) and 0.05 microns of alumina. To remove the alumina particles remaining on the electrode surface, a new alumina polishing pad was then used to polish the electrode for a few seconds. The electrode surface was rinsed with distilled water and dried with $\mathrm{N}_{2}$. Cyclic voltammetry (CV) was carried out in a Faraday cage with three electrode system using an Autolab potentiostat (Metrohm-Autolab BV, Netherlands) at 298 K. The Pt microelectrode was used as the working electrode, an Ag wire as the pseudo-reference electrode and a platinum foil as the counter electrode. Cyclic voltammetry at the Pt microelectrode was recorded in the as-prepared ultra-low conductivity $\mathrm{H}_{2} \mathrm{O}$, degassed Millipore water and $0.2 \mathrm{M}$ $\mathrm{NaF}$ aqueous solution respectively. All the above solutions were degassed with Ar for at least 10 min to remove the dissolved oxygen with electrodes in the solution before the electrochemical measurements.

\section{Acknowledgements}

The research is supported by the European Research Council (ERC) under the EuropeanUnion's Seventh Framework Programme (FP/2007-2013), ERCGrant Agreement no. 320403. The China Scholarship Council is gratefully acknowledged for funding X. Li's

PhD course. E. Laborda thanks the financial support of the Fundación Séneca de la Región de Murcia (18968/JLI/13 and 19887/GERM/15) and the MINECO (Spanish Government, Project CTQ2015-65243-P and Juan de la Cierva Fellowship). 
Keywords: Aqueous voltammetry; Ion-exchange resin beads; Low conductivity solution;

Absence of supporting electrolyte; Microelectrode

\section{Notes and References}

[1] W. J. Albery, Electrode kinetics, Clarendon Press, 1975.

[2] a) E. J. F. Dickinson, J. G. Limon-Petersen, N. V. Rees, R. G. Compton, J. Phys. Chem. C 2009, 113, 11157-11171; b) S. R. Belding, J. G. Limon-Petersen, E. J. F. Dickinson, R. G. Compton, Angew. Chem. 2010, 122, 9428-9431.

[3] a) A. M. Bond, M. Fleischmann, J. Robinson, J. Electroanal. Chem. Interfacial Electrochem. 1984, 168, 299-312; b) M. J. Peña, M. Fleischmann, N. Garrard, J. Electroanal. Chem. Interfacial Electrochem. 1987, 220, 31-40; c) C. Amatore, M. R. Deakin, R. M. Wightman, J. Electroanal. Chem. 1987, 225, 49-63; d) J. Heinze, Angew. Chem., Int. Ed. Engl. 1993, 32, 1268-1288; e) M. Ciszkowska, Z. Stojek, J. Electroanal. Chem. 1999, 466, 129-143; f) M. Ciszkowska, Z. Stojek, Anal. Chem. 2000, 72, 754 A-760 A.

[4] a) R. M. Wightman, Anal. Chem. 1981, 53, 1125A-1134A; b) J. O. Howell, R. M. Wightman, Anal. Chem. 1984, 56, 524-529; c) A. M. Bond, P. A. Lay, J. Electroanal. Chem. Interfacial Electrochem. 1986, 199, 285-295; d) J. B. Cooper, A. M. Bond, J. Electroanal. Chem. Interfacial Electrochem. 1991, 315, 143-160; e) S. M. Drew, R. M. Wightman, C. A. Amatore, J. Electroanal. Chem. Interfacial Electrochem. 1991, 317, 117-124; f) K. B. Oldham, T. J. Cardwell, J. H. Santos, A. M. Bond, J. Electroanal. Chem. 1997, 430, 39-46; g) M. F. Bento, L. Thouin, C. Amatore, M. I. Montenegro, J. Electroanal. Chem. 1998, 443, 137-148; h) A. M. Bond, K. B. Oldham, G. A. Snook, Anal. Chem. 2000, 72, 3492-3496.

[5] a) M. Ciszkowska, Z. Stojek, J. Electroanal. Chem. Interfacial Electrochem. 1986, 213, 189-201; b) A. Jaworski, M. Donten, Z. Stojek, Anal. Chim. Acta 1995, 305, 106-113; c) D. Pletcher, S. Sotiropoulos, J. Chem. Soc. Faraday Trans. 1995, 91, 457-462.

[6] T. S. Light, Anal. Chem. 1984, 56, 1138-1142.

[7] H. S. Harned, R. Davis Jr, J. Am. Chem. Soc. 1943, 65, 2030-2037.

[8] D. A. J. Rand, R. Woods, J. Electroanal. Chem. Interfacial Electrochem. 1972, 35, 209-218.

[9] B. E. Conway, H. Angerstein-Kozlowska, W. B. A. Sharp, E. E. Criddle, Anal. Chem. 1973, 45, 1331-1336. 
[10] P. Sun, M. V. Mirkin, Anal. Chem. 2006, 78, 6526-6534.

[11] R. G. Compton, C. E. Banks, Understanding Voltammetry, 2 ed., Imperial College Press, London, 2011.

[12] The possibility of $\mathrm{FcCH}_{2} \mathrm{OH}$ dissociation can not be completely excluded.

[13] K. B. Oldham, J. Electroanal. Chem. Interfacial Electrochem. 1988, 250, 1-21.

[14] It was observed that the yellow of $\mathrm{FcCH}_{2} \mathrm{OH}$ solution became obviously lighter after treatment with the IEx resin beads and the cation exchange resin beads turned into dark green after long time exposure to oxygen due to the formation of ferrocenium from the oxidation of the adsorbed ferrocene.

[15] E. Wilhelm, R. Battino, R. J. Wilcock, Chem. Rev. 1977, 77, 219-262.

[16] C. Lin, X. Jiao, K. Tschulik, C. Batchelor-McAuley, R. G. Compton, J. Phys. Chem. C 2015, 119, 16121-16130.

[17] K. Tschulik, W. Cheng, C. Batchelor-McAuley, S. Murphy, D. Omanović, R. G. Compton, ChemElectroChem 2015, 2, 112-118.

[18] A. N. Frumkin, Z. Phys. Chem. 1933, 164.

[19] P. P. Edwards, H. B. Gray, M. T. J. Lodge, R. J. P. Williams, Angew. Chem. Int. Ed. 2008, 47, 6758-6765.

[20] P. Gies, R. R. Gerhardts, Phys. Rev. B 1985, 31, 6843-6845.

[21] a) E. J. F. Dickinson, R. G. Compton, J. Phys. Chem. C 2009, 113, 17585-17589; b) J. D. Norton, H. S. White, S. W. Feldberg, J. Phys. Chem. 1990, 94, 6772-6780; c) R. He, S. Chen, F. Yang, B. Wu, J. Phys. Chem. B 2006, 110, 3262-3270.

[22] a) A. Gray-Weale, J. K. Beattie, Phys. Chem. Chem. Phys. 2009, 11, 10994-11005; b) R. Kumar, C. Knight, G. A. Voth, Faraday Discuss. 2013, 167, 263-278.

[23] A. M. Bond, M. Fleischmann, J. Robinson, J. Electroanal. Chem. Interfacial Electrochem. 1984, 172, 11-25. 
Graphical Abstract

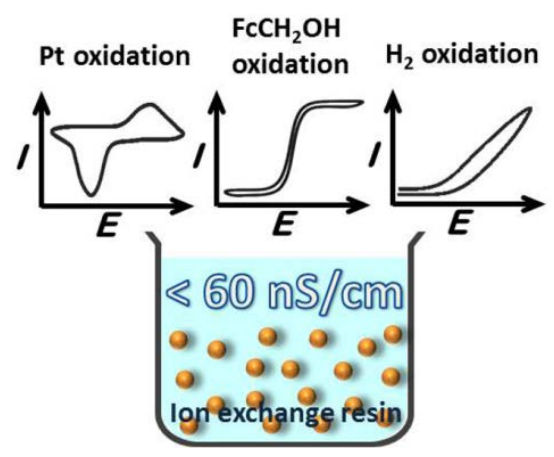

The near minimum conductivity $\left(\sim 60 \mathrm{nS} \mathrm{cm}^{-1}\right)$ for an aqueous solution is achieved through in-situ deionization with ion exchange resin beads. The feasibility of electrochemical reaction in aqueous media in the near absence of the supporting electrolyte is demonstrated. 